\title{
Effect of deformation rate on the mechanical properties of arteries
}

\author{
Jorge O. Virues Delgadillo ${ }^{1}$, Sebastien Delorme ${ }^{2}$, Vincent Mora ${ }^{2}$, Robert DiRaddo ${ }^{2}$, \\ Savvas G. Hatzikiriakos ${ }^{1}$
}

${ }^{1}$ Department of Chemical \& Biological Engineering, UBC, Vancouver, BC, Canada

${ }^{2}$ Industrial Materials Institute, National Research Council of Canada, Boucherville, QC, Canada

Email: hatzikir@interchange.ubc.ca; Sebastien.Delorme@imi.cnrc-nrc.gc.ca

Received 27 June 2008; revised 18 December 2009; accepted 20 December 2009.

\begin{abstract}
Pig aorta samples were tested uniaxially and equibiaxially at deformation rates from 10 to $200 \% / \mathrm{s}$. Under uniaxial and biaxial testing, loading forces were reduced up to $20 \%$ when the deformation rate was increased from 10 to $200 \% / \mathrm{s}$, which is the opposite to the behaviour seen in other biological tissues. A rate-dependent isotropic hyperelastic constitutive equation, derived from the Mooney-Rivlin model, was fitted to the experimental results (e.g. aorta specimens) using an inverse finite element technique. In the proposed model, one of the material parameters is a linear function of the deformation rate. The inverse relationship between stiffness and deformation rate raises doubts on the hypothesized relationship between intramural stress, arterial injury, and restenosis.
\end{abstract}

Keywords: Mechanical Properties; Artery; Uniaxial \& Biaxial Testing; Deformation Rate; Viscoelasticity; Constitutive Model

\section{INTRODUCTION}

The knowledge of the viscoelastic properties is important to predict the biomechanical behaviour of soft tissues. To model their viscoelastic behaviour, first one performs appropriate mechanical tests to characterize deformation-rate effects, and then one selects a constitutive equation capable of representing those effects. Material parameter estimation is fundamental for posterior simulation of soft tissue at boundary conditions not selected in the experimental protocol.

The effect of deformation rate on the mechanical properties of soft biological tissues has been investigated, in particular for ligaments [1-7], tendons [4,7-9], spines [10-13], bones [14-17], liver [18], heart valves [19,20] and myocardium [21,22]. Most biological tissues stiffen with increasing deformation rate $[4,7,9,11-13,17]$. This time-dependent behavior has been described by viscoelastic constitutive models [6,22-26]. However, it was recently demonstrated that some biological tissues, such as liver, myocardium and skin, soften with increasing deformation rate $[18,22]$. Deformation rate effects of arteries, in particular thoracic aorta, were not included in previous studies.

Overstretch injury to the arterial wall during an angioplasty or stenting procedure has been shown to be correlated to the incidence of restenosis, i.e. in-growing tissue re-blocking the artery lumen [26,27]. Based on the hypothesis that lower deformation rate results in lower intramural stresses, slow balloon inflation has been proposed as a means to minimize vascular injury and reduce restenosis incidence [28]. Early studies did not conclude there was any difference in restenosis rates between conventional and slow balloon inflation [28-30], while some observed better immediate results $[31,32]$. In more recent studies, significantly lower restenosis rates were clinically observed with slow balloon inflation [33,34]. Slow stent deployment has also been proposed as a means to minimize arterial injury [35].

Finite element simulation of angioplasty and stenting can be used to optimize angioplasty procedure parameters, such as inflation pressure [36-40]. Optimization of inflation pressure rate requires accurate constitutive modeling of artery behavior including the effect of deformation rate. Numerous experimental studies have been performed to characterize the mechanical behaviour of arteries in vitro [41-44]. However, only a single deformation rate was used.

The objective of this study is thus to measure and model the effect of deformation rate on the tensile behavior of the arteries (e.g. pig aortas). In other words, the intention of this paper is to investigate experimentally the dependence of uniaxial and biaxial extensional stretching of arterial wall on the deformation-rate, and consequently to modeling the experimental data by means of an appropriate constitutive equation. 


\section{MATERIALS AND METHODS}

\subsection{Experimental Setup}

Five thoracic aortas were harvested within the day of death of pigs from a local slaughterhouse and cleaned of remaining connective tissue. Then each artery was cut open along its length, and cut out in rectangular and cruciform-shaped specimens. The thickness of all specimens was measured with a vernier caliper (mean $2.4 \mathrm{~mm}$, standard deviation $0.2 \mathrm{~mm}$ ). Twelve samples were obtained from the five aortas: 8 rectangular samples $(4$ were cut in circumferential direction and 4 in axial direction) and 4 cruciform samples. Samples were stored in isotonic saline solution at $4^{\circ} \mathrm{C}$ for no longer than 8 hours prior to testing.

Rectangular and cruciform samples were used for uniaxial and biaxial testing, respectively. Rectangular samples were $40 \mathrm{~mm}$ long and $4 \mathrm{~mm}$ wide, but only $20 \mathrm{~mm}$ of the sample were free to deform. The distance between grips in cruciform samples was $40 \mathrm{~mm}$. A nominal stretch ratio of 1.5 was applied to avoid permanent deformation on the tissue.

Uniaxial and biaxial testing was carried on a planar biaxial test bench (Bose Corporation, Minnetonka, MN) capable of applying a peak force of $200 \mathrm{~N}$ over a displacement range of $12 \mathrm{~mm}$ per actuator. A saline bath maintained at body temperature $\left(37^{\circ} \mathrm{C}\right)$ was used. Samples were mounted in horizontal configuration with the help of grip clamps to the arms extending from the actuators over the top of the bath.

Each sample was subjected to triangular wave form displacements of 1.5 stretch ratio of amplitude, and deformation rates of $10,50,100,120,140,160,180$ and $200 \% / \mathrm{s}$, which correspond to frequencies of $0.1,0.5,1.0$, $1.2,1.4,1.6,1.8$ and $2.0 \mathrm{~Hz}$. Half of the samples were subjected to deformation rates in the following order: $160,120,50,200,140,100,10$ and $180 \% / s$ (randomly tested), and the other half were tested from 10 to 200 $\% / \mathrm{s}$ in ascending order in order to be confident that the deformation rate effect observed do not depend on the testing procedure order. In vivo, the artery is constantly submitted to stresses while the tissue is inflated-deflated due to blood pressure. In order to mimic in vivo loading conditions during in vitro tests, pre-conditioning cycles are required. Each test lasted for ten cycles. The first five cycles were used to pre-condition the tissue in order to reach a steady-state behavior. The force-stretch data was averaged over the last five cycles.

\subsection{Statistical Analysis}

The experimental data obtained in uniaxial and biaxial testing are represented in mostly all figures in this chapter as the mean value \pm the standard errors (i.e. Figure $3)$. The medians rather than the means are plotted only in Figure 6. As shown in Table 1, twenty loading-unloading cycles were used to obtain the circumferential and axial force-stretch mean curves per deformation rate and testing condition. Circumferential and axial forces at 1.5 stretch ratio from both uniaxial and biaxial tests were used to calculate the medians, ranges (percentile between 75\%-25\%) and $p$ values with the help of the statistical tests selected. A multiple comparison between forces belonging to all groups (i.e. experimental forces obtained at each deformation rate belong to one group) was performed to study the significance of the effect of deformation rate using the ANOVA Friedman statistic test for dependent variables. The Wilcoxon test was also used to compare all deformation rate forces by pairs (i.e. forces at the highest deformation rate, $200 \% / \mathrm{s}$, with forces at the lowest deformation rate, $10 \% / \mathrm{s}$ ). In order to identify if the effect of deformation rate is more significant than the effect of anisotropy, circumferential and axial forces at each deformation rate were also compared using the Wilcoxon test. A 0.05 level of significance $(p=0.05)$ were selected for the Friedman and Wilcoxon tests.

\subsection{Inverse Modeling}

An inverse modeling technique was used to adjust the parameters of the proposed constitutive model (described below in the results section). The reaction forces at the boundaries (grips) were predicted by finite element simulation of the experiment consisting of applying displacement conditions on a mesh of the same size and shape as the sample. In an optimization loop, the material properties were iteratively adjusted until the following objective function was minimized, which occurs when a set of force-displacement experimental data matches the values calculated by the model:

$$
S(c)=S(c)_{\text {Biaxial }}+S(c)_{\text {Uniaxial }}
$$

The objective function to be minimized is the sum of uniaxial and biaxial cruciform objective functions.

Table 1. Number of force-stretch experimental data averaged per deformation rate.

\begin{tabular}{ccccc}
\hline Testing condition & Specimen direction & Number of specimens & Number of cycles per specimen & Total number of cycles \\
\hline Uniaxial & Circumferential & 4 & 5 & 5 \\
Biaxial & Axial & - & 4 & 5 \\
\hline
\end{tabular}




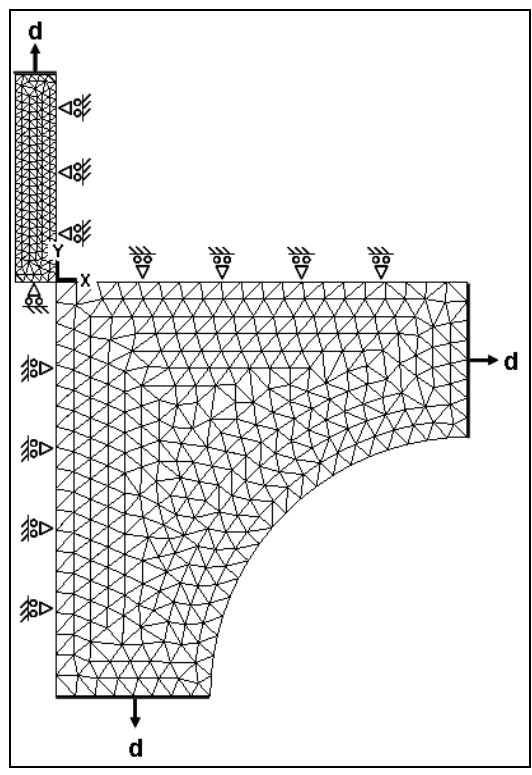

Figure 1. Mesh and boundary conditions used in simultaneous simulation of uniaxial and biaxial testing.

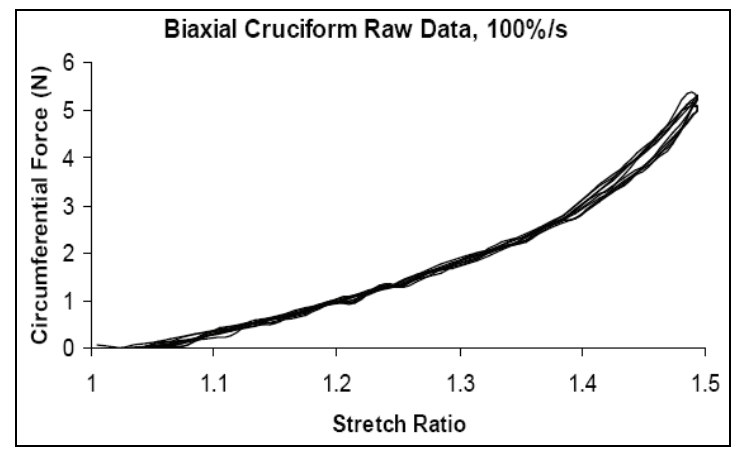

Figure 2. Loading-unloading circumferential forcestretch cycles of a typical biaxial cruciform sample: Five steadystate cycles at a deformation rate of $100 \% / \mathrm{s}$.

$$
S(c)_{\text {Biaxial }}=\sum_{i=1}^{N}\left[\begin{array}{l}
\left.\left.\left(F_{x}\left(d_{x}, d_{y}\right)-f_{x}\left(d_{x}, d_{y}, c\right)\right)^{2}+\right]_{y}\left(d_{x}, d_{y}\right)-f_{y}\left(d_{x}, d_{y}, c\right)\right)^{2}
\end{array}\right]_{i}
$$

where $c$ is the vector of unknown material properties; $d_{x}$ and $d_{y}$ are the applied displacements; $F_{x}\left(d_{x}, d_{y}\right)$ and $F_{y}\left(d_{x}, d_{y}\right)$ are the experimentally measured reaction forces at the grips; and $f_{x}\left(d_{x}, d_{y}, c\right)$ and $f_{y}\left(d_{x}, d_{y}, c\right)$ are the reaction forces predicted by the finite element model in biaxial cruciform extension; $N$ is the total number of data points gathered in the experiments.

$$
S(c)_{\text {Uniaxial }}=\sum_{i=1}^{N}\left[(F(d)-f(d, c))^{2}\right]_{i}
$$

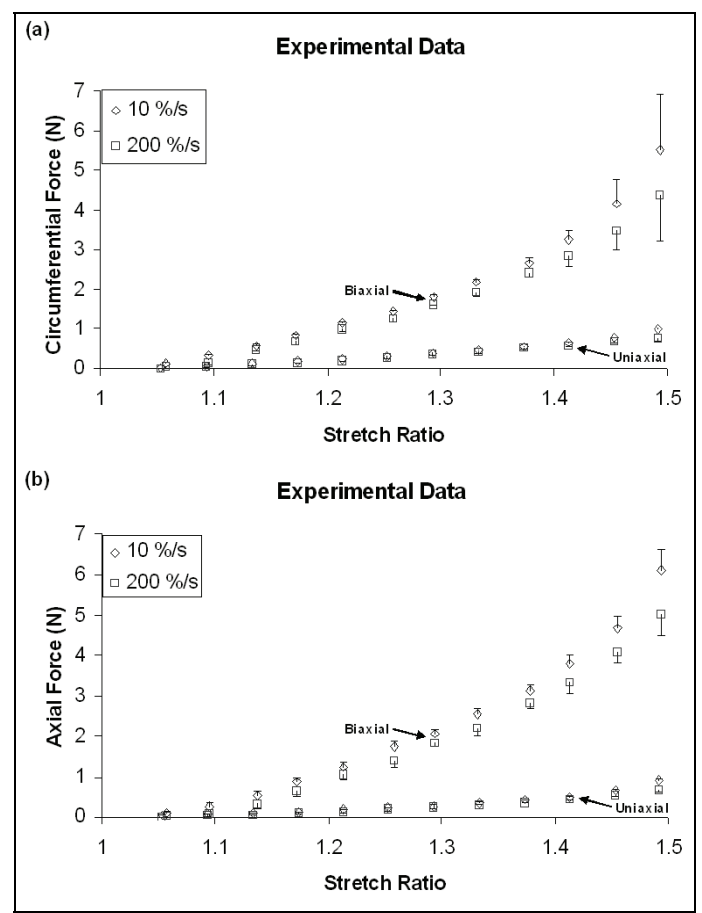

Figure 3. Sample to sample variability of thoracic aorta. Open diamonds and squares represent the mean force-stretch behavior at 10 and $200 \%$ /s, respectively $(n=4)$ : (a) circumferential, and (b) axial directions. Standard error bars are also shown.

Uniaxial extension predicted forces $(f(d, c))$ were fitted to the average of circumferential and axial reaction forces $(F(d)) ; d$ is the applied displacement in uniaxial extension.

A combined uniaxial-biaxial mesh was used to simultaneously simulate uniaxial and biaxial testing conditions (Figure 1). Only one quarter of the rectangular and the cruciform sample area free to deform between the grips was meshed due to symmetry. The uniaxial and biaxial cruciform mesh-sections are linked together at the origin. Boundary conditions are shown in Figure 1. In some cases, a small stretch shift was applied to the experimental results to obtain better agreement between uniaxial and biaxial fits.

\section{RESULTS}

\subsection{Experimental Results}

Figure 2 shows cycle-to-cycle variability between cycles 6 and 10, for a typical sample tested biaxially at a deformation rate of $100 \% / \mathrm{s}$. Cycle-to-cycle variability was observed to be small for all cases.

Figure 3 shows the standard error bars (sample-tosample variability) of circumferential and axial forces at the lowest $(10 \% / \mathrm{s})$ and highest $(200 \% / \mathrm{s})$ deformation 
rates. Similar standard errors were obtained with the other deformation rates.

Figure 4 shows the effect of deformation rate on the circumferential behavior of thoracic aorta from uniaxial and biaxial testing. Lower forces were observed at higher than at lower deformation rates. In particular, a $20 \%$ lower force was observed at 1.5 stretch ratio with the lowest deformation rate $(10 \% / \mathrm{s})$ compared to the highest deformation rate $(200 \% / \mathrm{s})$. The same phenomenon was observed in the axial direction (Figure 5).

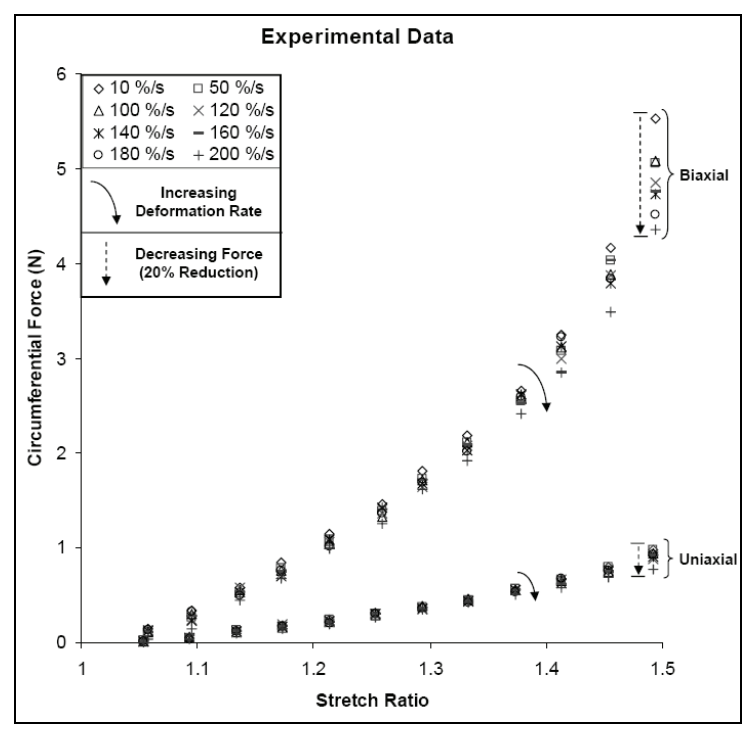

Figure 4. Effect of deformation rate on the force vs. stretch ratio curve of arteries: Circumferential force vs. stretch ratio curves in uniaxial and biaxial testing.

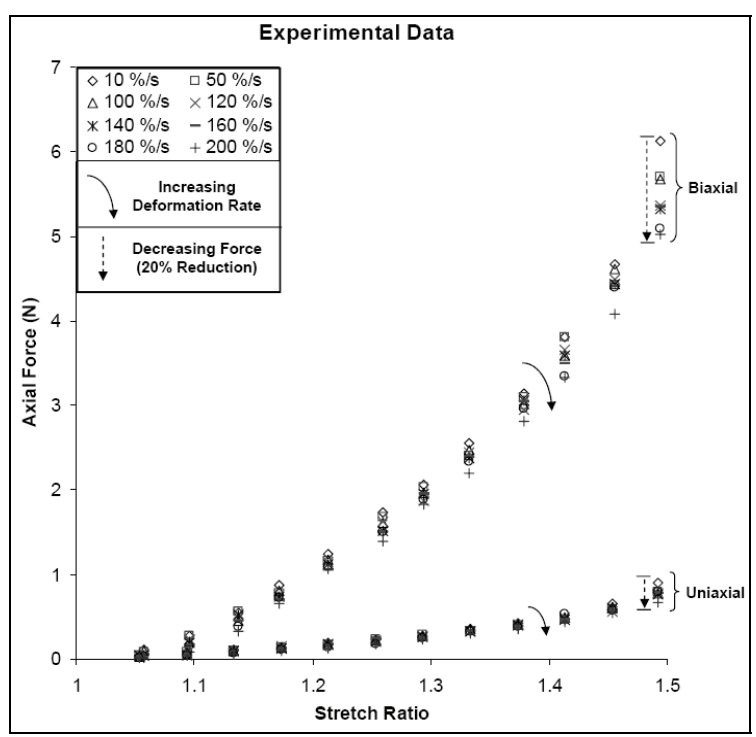

Figure 5. Effect of deformation rate on the force vs. stretch ratio curve of arteries: Axial force vs. stretch ratio curves in uniaxial and biaxial testing.
Figure 6 shows the median, percentiles $(75 \%-25 \%)$ and the ANOVA Friedman test $p$ value obtained using the forces at 1.5 stretch ratio for each deformation rate. Significant differences $(p<0.05)$ were observed, with the highest significant differences under biaxial testing $(p \leq 0.002)$.

Table 2 shows Wilcoxon test $p$ values of uniaxial and biaxial data of some of the deformation rate pairs analyzed (i.e. comparison of the force at the maximum deformation rate with the forces at other deformation rates). Marginally significant differences were observed in the forces of mostly all deformation rates. Similar $p$ values were obtained in the other comparisons (i.e. $50 \% / \mathrm{s}$ vs. all deformation rates).

In Figure 7, circumferential and axial forces at 1.5 stretch ratio of a typical sample are plotted against deformation rate. In this figure, one can observe that the effect of deformation rate $(20 \%$ difference in force between smallest and highest deformation rate) is approximately twice as large as the effect of anisotropy (difference in force between circumferential and axial directions). This supports the hypothesis of modelling deformation-rate effects with an isotropic model.

Table 3 shows $p$ values calculated using the Wilcoxon test comparing the circumferential force to the axial force at 1.5 stretch ratio per each deformation rate.

\subsection{Constitutive Modeling}

Based on the experimental results, it was assumed that the arterial wall behaves as a pseudoelastic material [45], where the stress is independent of the loading path. Thus, we propose a new rate-dependant isotropic hyperelastic model, based on the Mooney-Rivlin model [46] given by the following strain energy density function:

$$
W\left(I_{1}, I_{2}\right)=\sum_{i, j=0}^{\infty} a_{i j}\left(I_{1}-3\right)^{i}\left(I_{2}-3\right)^{j}
$$

The Mooney-Rivlin model is a function of the $1^{\text {st }}$ and $2^{\text {nd }}$ invariants $\left(I_{1}, I_{2}\right)$ of the Green-Cauchy tensor:

$$
\begin{gathered}
I_{1}=\lambda_{1}^{2}+\lambda_{2}^{2}+\lambda_{3}^{2} \\
I_{2}=\lambda_{1}^{2} \lambda_{2}^{2}+\lambda_{2}^{2} \lambda_{3}^{2}+\lambda_{3}^{2} \lambda_{1}^{2}
\end{gathered}
$$

where $\lambda_{1}, \lambda_{2}$ and $\lambda_{3}$ are the principal stretch ratios.

In its most common expression, only five parameters are selected $\left(a_{10}, a_{01}, a_{11}, a_{20}, a_{30}\right)$ and the strain energy function reduces to:

$$
\begin{aligned}
W & =a_{10}\left(I_{1}-3\right)+a_{01}\left(I_{2}-3\right)+a_{11}\left(I_{1}-3\right)\left(I_{2}-3\right) \\
& +a_{20}\left(I_{1}-3\right)^{2}+a_{30}\left(I_{1}-3\right)^{3}
\end{aligned}
$$

The underlying hypothesis for using the MooneyRivlin model is that one or some of the five parameters vary with deformation rate. This can be modeled by 

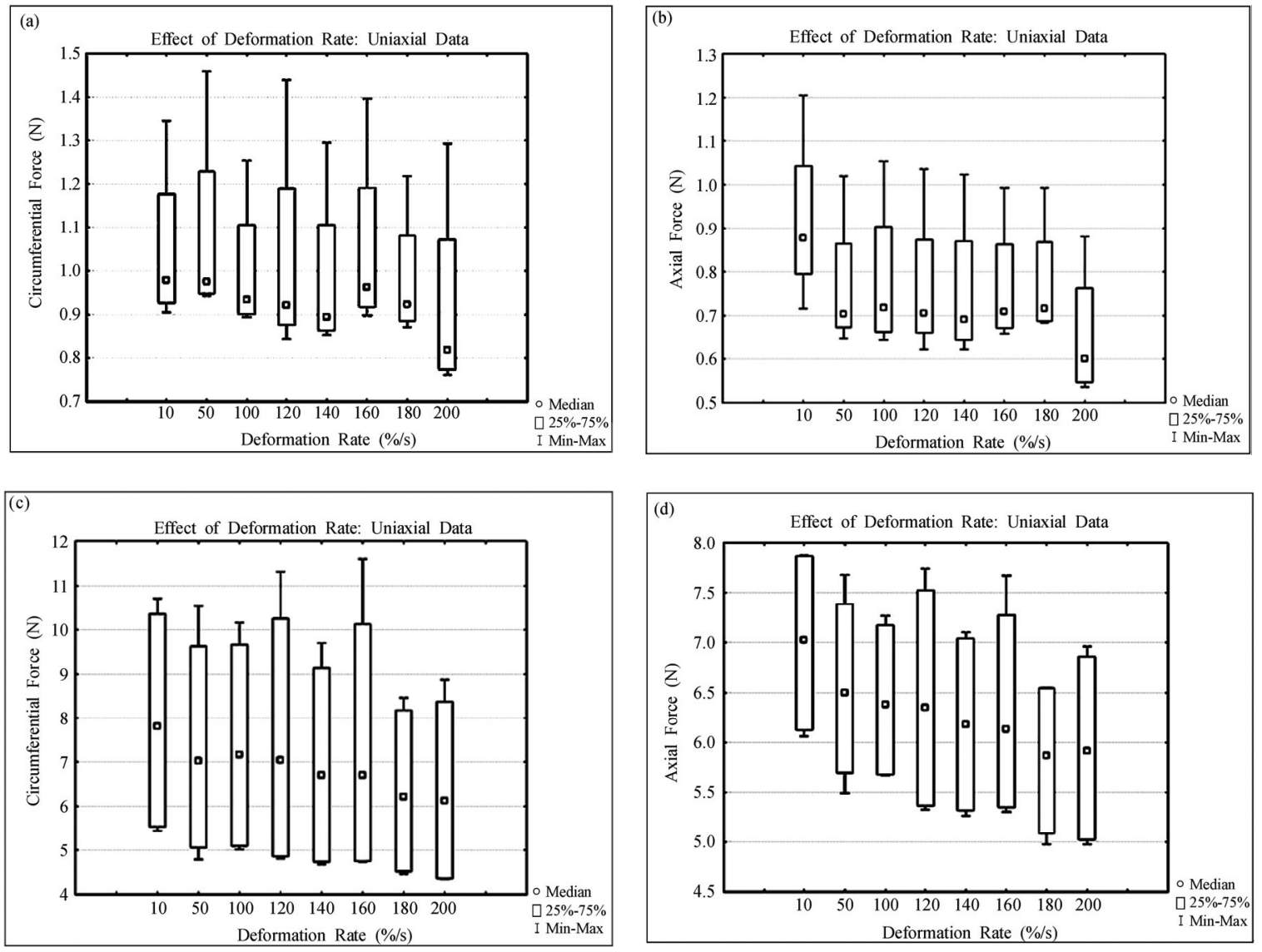

Figure 6. Deformation rate effect on $(a, b)$ uniaxial and $(\mathrm{c}, \mathrm{d})$ biaxial forces at maximum stretch ratio $(\lambda=1.5)$ : $(\mathrm{a}, \mathrm{c})$ circumferential and $(b, d)$ axial direction.

Table 2. Effect of deformation rate:Wilcoxon test $p$ values.

\begin{tabular}{ccccc}
\hline Type of test & \multicolumn{2}{c}{ Uniaxial } & \multicolumn{2}{c}{ Biaxial } \\
\hline Force & Circumferential & Axial & Circumferential & Axial \\
\hline Deformation rate (\%/s) & & & 200 & \\
\hline 10 & 0.07 & 0.07 & 0.07 & 0.07 \\
50 & 0.07 & 0.07 & 0.07 & 0.07 \\
100 & 0.14 & 0.07 & 0.07 & 0.07 \\
120 & 0.07 & 0.07 & 0.07 & 0.07 \\
140 & 0.07 & 0.07 & 0.07 & 0.07 \\
160 & 0.07 & 0.07 & 0.07 & 0.07 \\
180 & 0.37 & 0.07 & 0.72 & 0.42 \\
\hline
\end{tabular}

Table 3. Effect of anisotropy (Circumferential vs. axial forces, $n=4$ ): Wilcoxon test $p$ values.

\begin{tabular}{ccc}
\hline Deformation rate $(\% / \mathbf{s})$ & Uniaxial & Biaxial \\
\hline 10 & 0.47 & 0.47 \\
50 & 0.14 & 0.47 \\
100 & 0.27 & 0.47 \\
120 & 0.14 & 0.47 \\
140 & 0.27 & 0.47 \\
160 & 0.14 & 0.47 \\
180 & 0.14 & 0.47 \\
200 & 0.14 & 0.47 \\
\hline
\end{tabular}


Table 4. First simulation results (material parameters) of uniaxial and biaxial cruciform tests.

\begin{tabular}{|c|c|c|c|c|c|c|}
\hline \multicolumn{7}{|c|}{ M-R Fitted Parameter Values (kPa) } \\
\hline 10 & 9.25 & 7.57 & 5.77 & 6.94 & 4.43 & 2.69 \\
\hline 50 & 9.21 & 7.45 & 5.45 & 6.58 & 3.64 & 2.09 \\
\hline 100 & 8.90 & 7.23 & 5.51 & 6.66 & 3.86 & 1.76 \\
\hline 120 & 9.46 & 7.66 & 5.38 & 6.52 & 3.03 & 1.66 \\
\hline 180 & 9.07 & 7.32 & 5.34 & 6.49 & 2.95 & 2.80 \\
\hline 200 & 8.86 & 7.17 & 5.24 & 6.36 & 2.80 & 1.90 \\
\hline \multicolumn{4}{|c|}{ Linear Regression Coefficients \& $R^{2}$} & \multicolumn{2}{|c|}{$\left(a_{i j}=A+B \dot{\lambda}\right)$} & \\
\hline $\mathrm{A}$ & 9.32 & 7.60 & 5.69 & 6.85 & 4.27 & \\
\hline
\end{tabular}

Table 5. Second simulation results (material parameters) of uniaxial and biaxial cruciform tests.

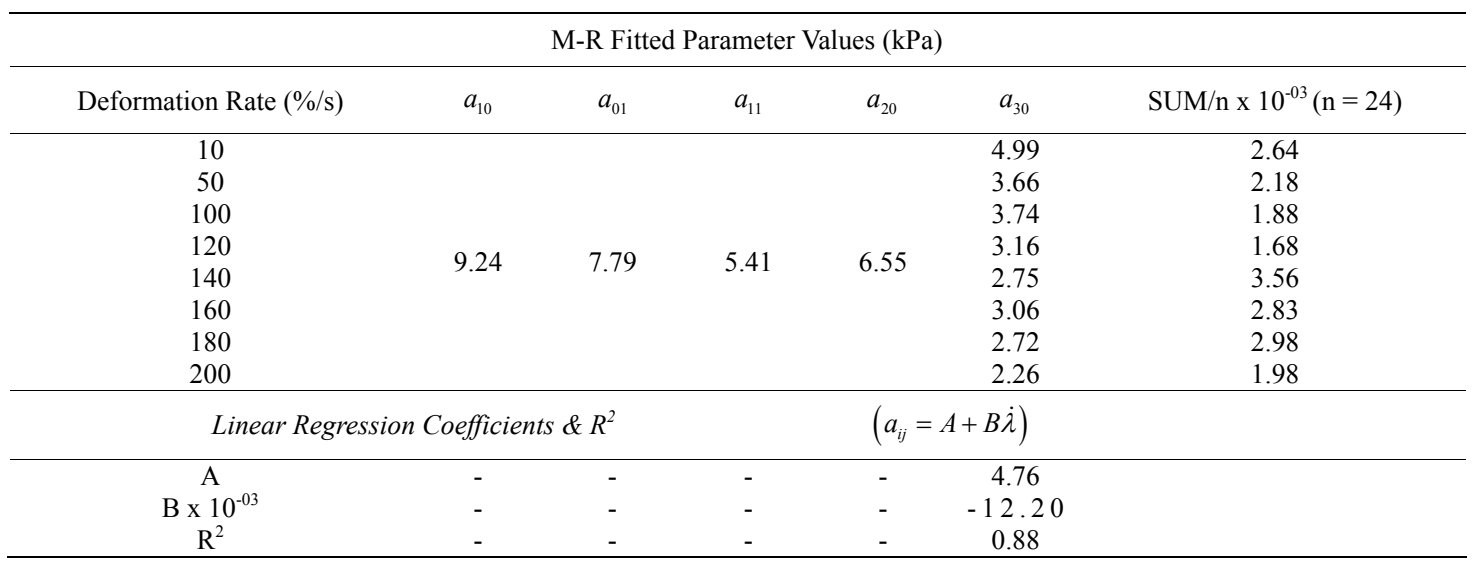

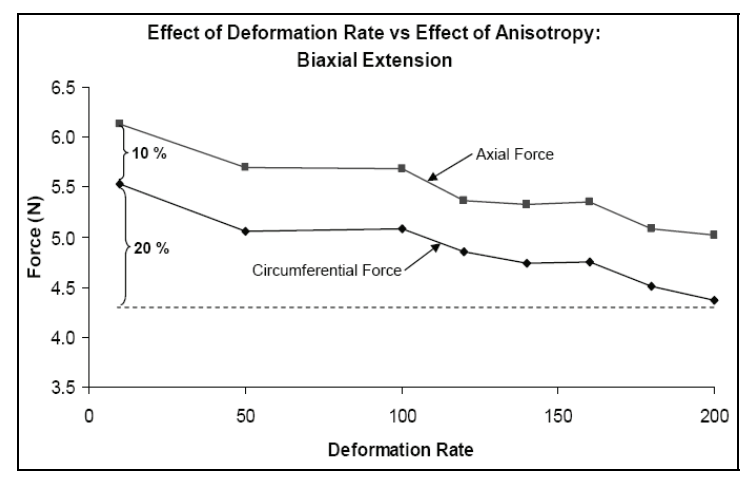

Figure 7. Comparison of the effect of deformation rate versus the effect of anisotropy. Typical sample forces at maximum stretch ratio (1.5).

making these parameters functions of the deformation rate. Those relationships are explored in this work.

\subsection{Inverse Modeling Results}

Initially, all five Mooney-Rivlin parameters were allowed to vary while being limited to a $10^{-4} \mathrm{kPa}$ to $10^{4} \mathrm{kPa}$ value range. Table 4 summarizes the fitted parameters obtained for the uniaxial and biaxial cruciform force vs. stretch ratio curve averaged for each deformation rate.

In a second simulation only parameter $a_{30}$ was allowed to vary because this was the parameter with the highest slope (absolute value of $B$ ) in the linear regressions reported in Table 4. The remaining parameters were maintained constant by using the average of the fitted values obtained for all deformation rates. The fitted parameters obtained are summarized in Table 5. The sum of least squares (last column in Tables 4 and 5) were almost unchanged when the first four parameters were kept constant, supporting the hypothesis that only $a_{30}$ varies with deformation rate.

Other fits were performed assuming that $a_{11}=a_{20}=0$ to see if the model could be reduced to a simpler form (Table 6). First, parameters $a_{10}, a_{01}$ and $a_{30}$ were allowed to vary. The highest regression coefficient (absolute value of $B$ ) and the highest correlationcoefficient $\left(R^{2}\right)$ were obtained for $a_{30}$. Thus parameters $a_{10}$ 
and $a_{01}$ were assumed to be constant (i.e. $a_{10}=12.59$ $\left.\mathrm{kPa}, a_{01}=9.54 \mathrm{kPa}\right)$ which were calculated as the average value of the fitted results obtained for all deformation rates. Parameter $a_{30}$ was fitted again (Table 7). The sum of least squares remained small although higher than in the Table 4. Repeated optimization with different initial parameter values consistently converged towards the same solution.

Uniaxial and biaxial simulations fitted values of pa- rameter $a_{30}$ (Table 7) are plotted against deformation rate in Figure 8. This parameter decreased from 11 to 8 $\mathrm{kPa}$ when the deformation rate increased from 10 to 200 $\% / \mathrm{s}$, respectively. A quadratic polynomial was also used to model the variation of $a_{30}$ with deformation rate but its correlation coefficient was similar to that obtained with a linear relationship, i.e. 0.89 and 0.88 respectively. Therefore, the linear fit was preferred over the polynomial fit due to its simplicity.

Table 6. Third simulation results (material parameters) of uniaxial and biaxial cruciform tests.

\begin{tabular}{ccccccc}
\hline \multicolumn{7}{c}{ M-R fitted parameter values (kPa) } \\
\hline Deformation rate (\%/s) & $a_{10}$ & $a_{01}$ & $a_{11}$ & $a_{20}$ & $a_{30}$ & $\mathrm{SUM} / \mathrm{n} \times 10^{-03}(\mathrm{n}=24)$ \\
\hline 10 & 12.90 & 9.72 & & & 10.76 & 2.61 \\
50 & 12.35 & 9.31 & & & 9.82 & 2.68 \\
100 & 12.39 & 9.35 & & & 9.86 & 3.61 \\
120 & 12.73 & 9.65 & 0.00 & 0.00 & 7.92 & 5.17 \\
140 & 13.38 & 10.14 & & & 9.12 & 3.40 \\
160 & 12.37 & 9.36 & & & 8.74 & 4.96 \\
180 & 12.27 & 9.35 & & & 8.17 & 4.09 \\
200 & 12.35 & 9.41 & & $\left(a_{i j}=A+B \dot{\lambda}\right)$ & \\
\multicolumn{2}{c}{ Linear regression coefficients $\& R^{2}$} & & - & 10.66 & \\
$\mathrm{~A}$ & 12.76 & 9.61 & - & - & -12.50 & \\
$\mathrm{~B} \mathrm{x} \mathrm{10-03}$ & -1.50 & -0.60 & - & - & 0.73 & \\
$\mathrm{R}^{2}$ & 0.07 & 0.02 & - &
\end{tabular}

Table 7. Final simulation results (material parameters) of uniaxial and biaxial cruciform tests.

\begin{tabular}{|c|c|c|c|c|c|c|}
\hline \multicolumn{7}{|c|}{$\mathrm{M}-\mathrm{R}$ fitted parameter values $(\mathrm{kPa})$} \\
\hline Deformation rate $(\% / s)$ & $a_{10}$ & $a_{01}$ & $a_{11}$ & $a_{20}$ & $a_{30}$ & $\mathrm{SUM} / \mathrm{n} \times 10^{-03}(\mathrm{n}=24)$ \\
\hline 10 & \multirow{8}{*}{12.59} & \multirow{8}{*}{9.54} & \multirow{8}{*}{0.00} & \multirow{8}{*}{0.00} & 10.91 & 2.62 \\
\hline 50 & & & & & 9.45 & 2.78 \\
\hline 100 & & & & & 9.53 & 2.70 \\
\hline 120 & & & & & 8.87 & 3.07 \\
\hline 140 & & & & & 8.41 & 5.33 \\
\hline 160 & & & & & 8.76 & 3.50 \\
\hline 180 & & & & & 8.38 & 5.13 \\
\hline 200 & & & & & 7.85 & 4.21 \\
\hline \multicolumn{4}{|c|}{ Linear regression coefficients $\& R^{2}$} & \multicolumn{2}{|c|}{$\left(a_{i j}=A+B \dot{\lambda}\right)$} & \\
\hline $\mathrm{A}$ & - & - & - & - & 10.66 & \\
\hline $\mathrm{B} \times 10^{-03}$ & - & - & - & - & -13.70 & \\
\hline $\mathrm{R}^{2}$ & - & - & - & - & 0.88 & \\
\hline
\end{tabular}

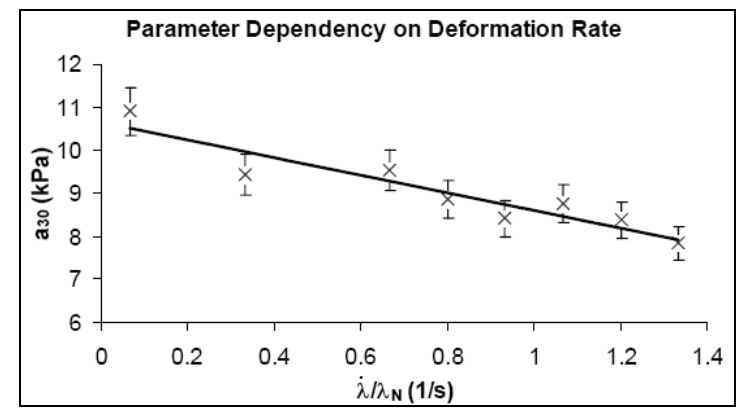

Figure 8. Parameter $a_{30}$ dependency on deformation rate for both, uniaxial and biaxial extensions. 
Table 8. Linear regression adjusted parameters.

\begin{tabular}{ccc}
\hline Parameter & Units & Uniaxial \& biaxial cruciform \\
\hline$A$ & $\mathrm{kPa}$ & 10.66 \\
$\hat{B}$ & $\mathrm{kPa}^{*} \mathrm{~s}$ & -2.06 \\
\hline
\end{tabular}

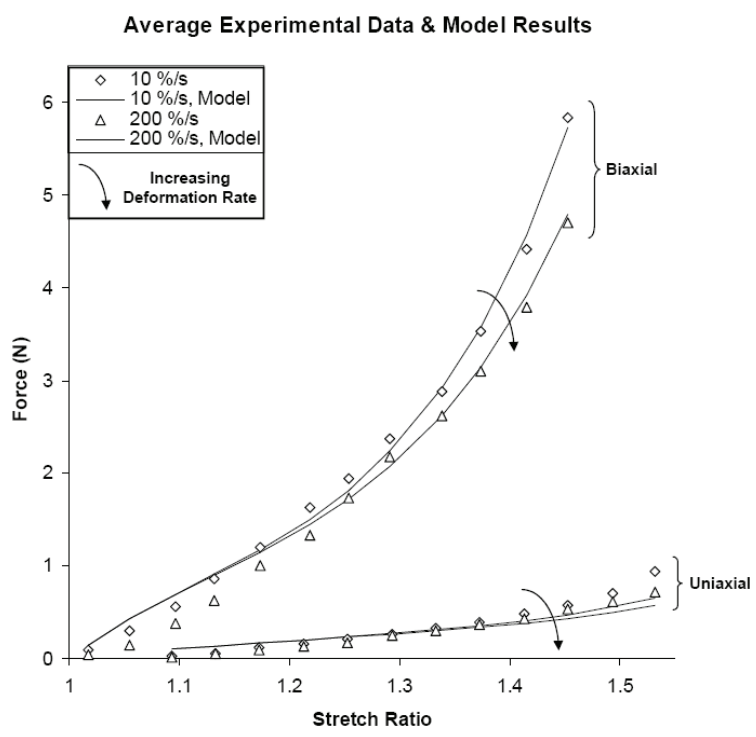

Figure 9. Mooney-Rivlin computed reaction forces versus stretch ratios in uniaxial and biaxial testing at 10 and 200 $\% / \mathrm{s}$. An increase in the deformation rate decreases the reaction forces at a particular stretch ratio.

The following linear equation is proposed for parameter $a_{30}$ :

$$
a_{30}=f(\dot{\lambda})=A+\hat{B}\left(\frac{\dot{\lambda}}{\lambda_{N}}\right)
$$

(a)

$$
\text { Minimization of the Objective Function }
$$

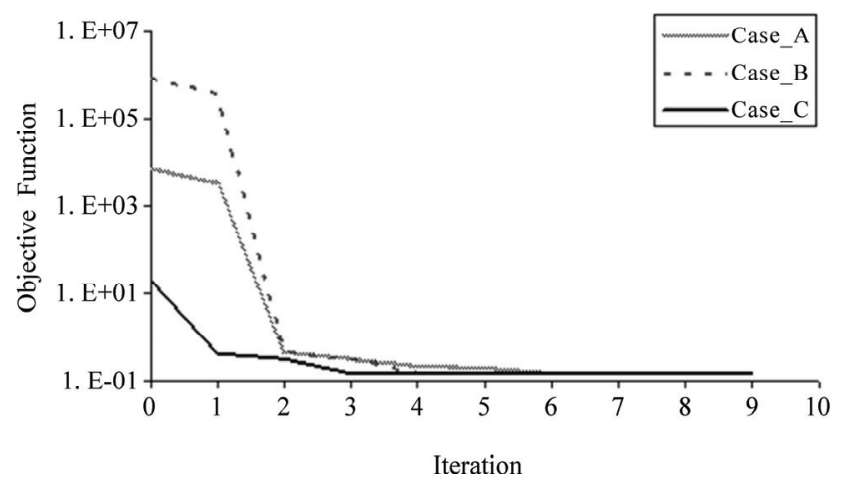

where $\dot{\lambda}$ is the deformation rate in $\mathrm{s}^{-1}, \lambda_{N}$ is the nominal stretch ratio $\left(\lambda_{N}=1.5\right), A$ and $\hat{B}$ are the linear regression coefficients. The strain rate was normalized by the nominal stretch ratio, in order to account for the biological variability in peak stretch of aorta samples. Table 8 summarizes the adjusted parameters of Equation 8.

Figure 9 shows the computed forces at the lowest (10 $\% / \mathrm{s})$ and highest $(200 \% / \mathrm{s})$ deformation rates. Circumferential and axial forces were averaged in order to clearly exemplify the model prediction of the arterial behavior when the deformation rate is increased.

Although an excellent fit is observed between the biaxial data and biaxial simulation, the Modified MooneyRivlin model does not predict well the uniaxial behavior, especially in the nonlinear part of the curve at high stretch ratios $(>1.45)$.

Minimization of the objective function and parameter $a_{30}$ estimation, using the data gathered at $100 \% / \mathrm{s}$ deformation rate, is shown in Figure 10. Figure 10a shows the value of the objective function plotted against the iteration number in the optimization loop, for three different initial guesses. The objective function was evaluated 50 times in iterations 0 (initial guess) to 9. Figure $10 \mathrm{~b}$ illustrates optimization of material parameter $a_{30}$.

Figure 11 shows the stress and stretch ratio distributions (at 1.5 stretch ratio) during uniaxial and biaxial testing. Scalar bars of the results at 10, 100 and $200 \% / \mathrm{s}$ deformation rates are shown for their comparison: One can observe the overall reduction of the stresses when the deformation rate was increased. The highest non uniform stress distribution was obtained in biaxial testing.

(b)

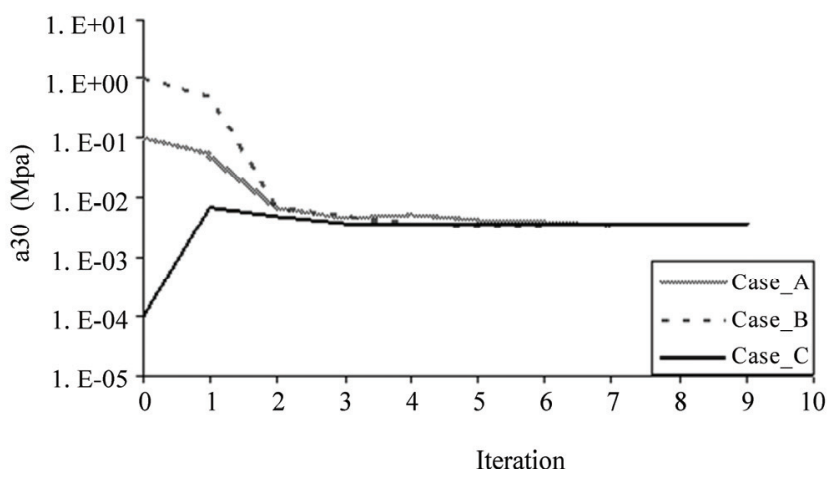

Figure 10. Optimization of the Mooney-Rivlin parameters for both uniaxial and biaxial tests at a deformation rate of $100 \%$. (a) objective function, and (b) parameter $a_{30}$ values as a function of iteration number, for three different initial guesses for material parameter $a_{30}$ : Case_A $\left(a_{30},=0.1 \mathrm{MPa}\right)$, Case_B $\left(a_{30},=1.0 \mathrm{MPa}\right)$, and Case_C $\left(a_{30},=0.0001 \mathrm{MPa}\right)$. 
(a)

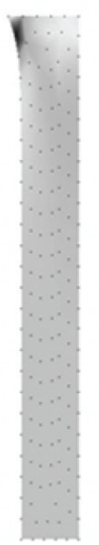

\begin{tabular}{|c|c|c|}
\hline \multicolumn{3}{|c|}{ StressDistribution (Mpa) } \\
\hline $10 \% / \mathrm{s}$ & $100 \% / \mathrm{s}$ & $200 \% / \mathrm{s}$ \\
\hline 0.096 & 0.090 & 0.084 \\
0.093 & 0.088 & 0.082 \\
0.091 & 0.085 & 0.080 \\
0.088 & 0.083 & 0.078 \\
0.086 & 0.081 & 0.076 \\
0.083 & 0.078 & 0.074 \\
0.081 & 0.076 & 0.072 \\
0.078 & 0.074 & 0.070 \\
0.076 & 0.071 & 0.068 \\
0.073 & 0.069 & 0.066 \\
\hline
\end{tabular}

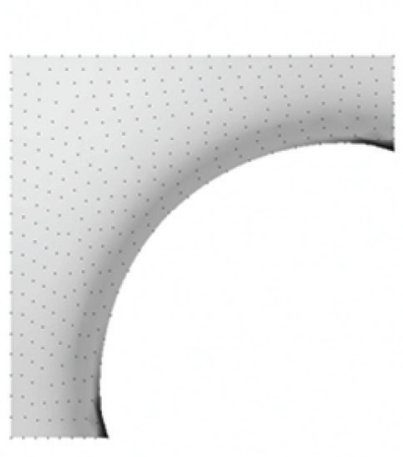

\begin{tabular}{|c|c|c|}
\hline \multicolumn{3}{|c|}{ StressDistribution (Mpa) } \\
\hline $10 \% / \mathrm{s}$ & $100 \% / \mathrm{s}$ & $200 \% / \mathrm{s}$ \\
\hline 0.752 & 0.752 & 0.633 \\
0.676 & 0.676 & 0.570 \\
0.601 & 0.601 & 0.507 \\
0.526 & 0.526 & 0.444 \\
0.450 & 0.450 & 0.381 \\
0.375 & 0.375 & 0.318 \\
0.299 & 0.299 & 0.255 \\
0.224 & 0.224 & 0.192 \\
0.148 & 0.148 & 0.129 \\
0.073 & 0.073 & 0.066 \\
\hline
\end{tabular}

(b)

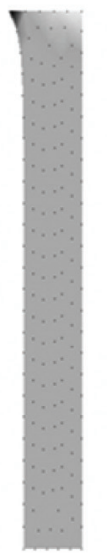

\begin{tabular}{|c|c|c|}
\hline \multicolumn{3}{|c|}{ Stretch Ratio Distribution } \\
\hline $10 \% / \mathrm{s}$ & $100 \% / \mathrm{s}$ & $200 \% / \mathrm{s}$ \\
\hline 1.517 & 1.520 & 1.518 \\
1.498 & 1.500 & 1.499 \\
1.479 & 1.479 & 1.480 \\
1.461 & 1.459 & 1.461 \\
1.442 & 1.439 & 1.442 \\
1.423 & 1.418 & 1.423 \\
1.404 & 1.398 & 1.404 \\
1.385 & 1.377 & 1.385 \\
1.367 & 1.357 & 1.366 \\
1.348 & 1.336 & 1.347 \\
\hline
\end{tabular}

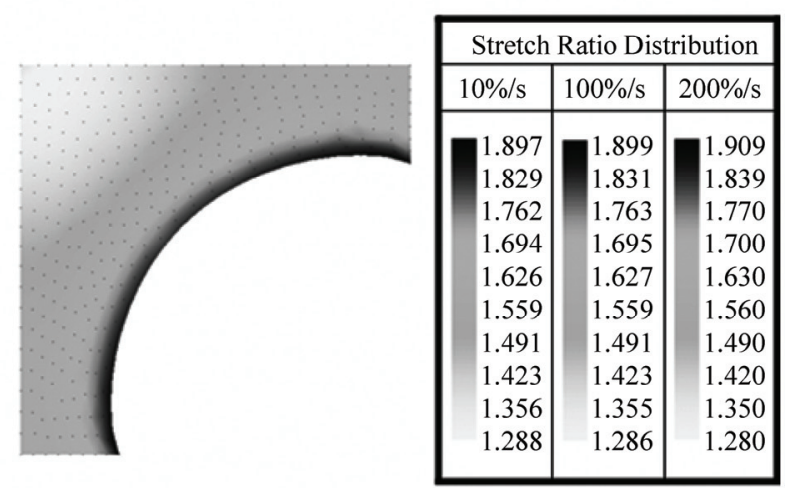

Figure 11. Deformed configurations at 1.50 nominal stretch ratio for uniaxial and cruciform mesh: Distribution of (a) $\sigma_{x x}$ stress and (b) stretch ratio in the principal direction. The stress and stretch distributions at 10, 100, and $200 \% / \mathrm{s}$ are shown inside the tables.

(a)

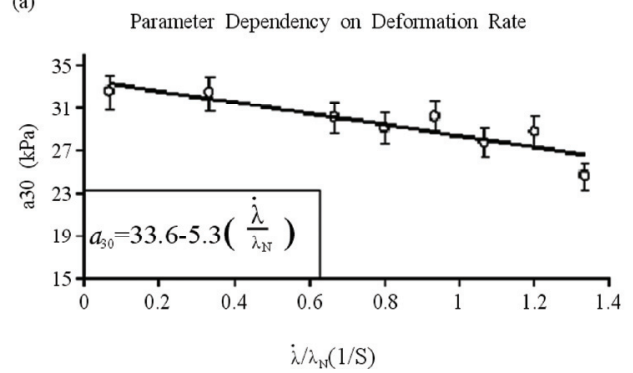

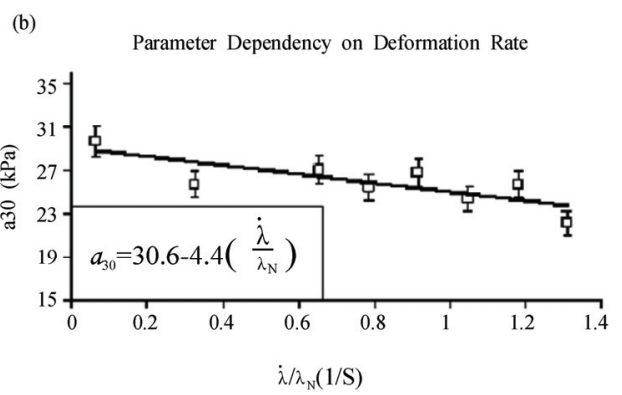

Figure 12. Parameter $\mathrm{a}_{30}$ dependency on deformation rate for uniaxial extension: (a) circumferential and (b) axial directions.

\subsubsection{Uniaxial Fit}

In order to improve uniaxial simulations, two objective functions were defined, one for each direction:

$$
\begin{aligned}
& S(c)=\sum_{i=1}^{N}\left[\left(F_{x}\left(d_{x}\right)-f_{x}\left(d_{x}, c\right)\right)^{2}\right]_{i} \\
& S(c)=\sum_{i=1}^{N}\left[\left(F_{y}\left(d_{y}\right)-f_{y}\left(d_{y}, c\right)\right)^{2}\right]_{i}
\end{aligned}
$$

These objective functions were used to better predict the uniaxial extension experimental data. Different material properties were obtained for the circumferential and for the axial directions.

Uniaxial simulations fitted values of parameter $a_{30}$ per deformation rates are shown in Figure 12. This parameter was reduced roughly from 33 to $23 \mathrm{kPa}$ when the deformation rate was increased, following the same 
Uniaxial, $100 \% / \mathrm{s}$

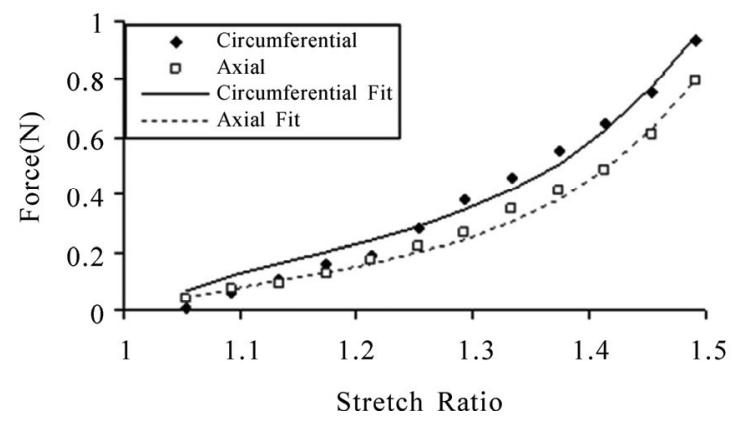

Figure 13. Mooney-Rivlin computed reaction forces versus stretch ratios in uniaxial testing at a deformation rate of $100 \% / \mathrm{s}$.

Table 9. Mooney-Rivlin fitted parameters in uniaxial extension.

\begin{tabular}{ccc}
\hline \multirow{2}{*}{ Mooney-Rivlin } & \multicolumn{2}{c}{ Parameters $(\mathrm{kPa})$} \\
\cline { 2 - 3 } & Circumferential & Axial \\
\hline$a_{10}$ & 9.56 & 9.56 \\
$a_{01}$ & 18.01 & 7.87 \\
$\mathrm{a}_{11}$ & 0.00 & 0.00 \\
$\mathrm{a}_{20}$ & 0.00 & 0.00 \\
$A$ & 33.64 & 30.62 \\
$\hat{B}$ & -5.32 & -4.40 \\
\hline
\end{tabular}

(a)

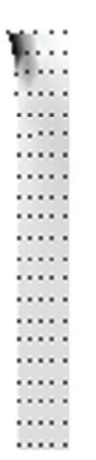

\begin{tabular}{|c|c|c|}
\hline \multicolumn{3}{|c|}{ StressDistribution (Mpa) } \\
\hline $10 \% / \mathrm{s}$ & $100 \% / \mathrm{s}$ & $200 \% / \mathrm{s}$ \\
\hline 0.201 & 0.192 & 0.171 \\
0.196 & 0.187 & 0.167 \\
0.191 & 0.182 & 0.163 \\
0.186 & 0.178 & 0.158 \\
0.181 & 0.173 & 0.154 \\
0.176 & 0.168 & 0.150 \\
0.171 & 0.163 & 0.146 \\
0.165 & 0.158 & 0.142 \\
0.160 & 0.153 & 0.137 \\
0.155 & 0.149 & 0.133 \\
\hline
\end{tabular}

Figure 14. Deformed configurations at 1.50 nominal stretch ratio for uniaxial mesh using the material parameters of Table 6.3 (Circumferential direction): distribution of (a) $\sigma_{x x}$ stress and (b) stretch ratio in the principal direction. The stress and stretch distributions at 10, 100, and $200 \%$ /s are shown inside the tables.

tissue behaviour, it was discovered in this study that the stiffness of thoracic aorta decreases with deformation rate, which was confirmed by the use of two statistical methods. Overall significant differences $(p \leq 0.02)$ in the mechanical forces of uniaxial and biaxial experiments were found using the ANOVA Friedman statistic test. In addition, the Wilcoxon test help us to observe which particular pair of deformation rates likely had a tendency to be significantly different (i.e. almost all deformation rates were different than $200 \% / \mathrm{s}, p=0.07$ ). An increase (b)

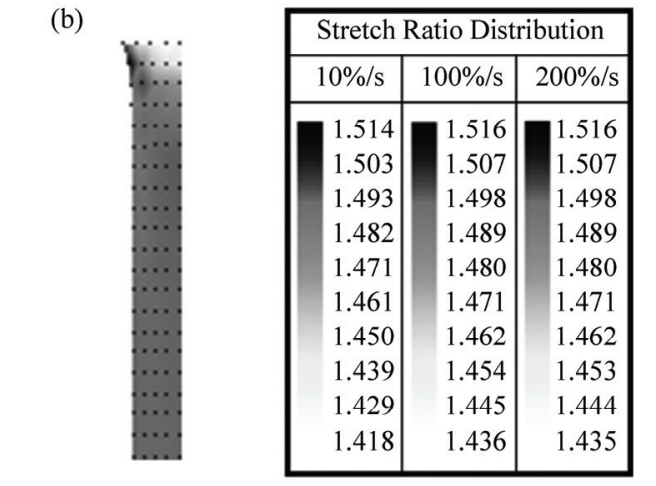

trend in circumferential and axial directions. It was also observed that material parameter $a_{30}$ changed linearly as a function of the deformation rate.

Table 9 summarizes Mooney-Rivlin fitted parameters obtained just for uniaxial tests. The values of $a_{30}$ obtained per deformation rate were almost 4 times greater than $a_{30}$ values calculated with the combined uniaxialbiaxial simulation. Parameters $a_{10}$ and $a_{01}$ remained almost unchanged in both the uniaxial and combined uniaxial-biaxial simulations, with exception of parameter $a_{01}$ in circumferential direction (i.e. $18 \mathrm{kPa}$ ).

The computed circumferential and axial forces obtained using the Mooney-Rivlin fitted parameters from Table 9 in uniaxial tests, at a deformation rate of $100 \% / \mathrm{s}$, are shown in Figure 13. Uniaxial behaviour in both directions was well predicted.

Figure 14 shows the stress and stretch ratio distribution of rectangular samples. The reduction of the stresses as the deformation rate increases is observed when the stress distribution at each deformation rate is compared (scalar bars at 10, 100 and $200 \% / \mathrm{s}$ ).

\section{DISCUSSION}

Contrary to the conventional understanding of biological 
ment controlled tests, Pioletti et al. [7] found that an increase in the deformation rate results in a stiffer material response. In their work, they submitted ligament samples to deformation rates within $0.1-40 \% / \mathrm{s}$ in ascending order. In the present study, thoracic aortas were tested over a $10-200 \% / \mathrm{s}$ range of deformation rates. In both, uniaxial and biaxial tests, the peak force on the arterial samples was around $20 \%$ smaller at a deformation rate of $200 \% / \mathrm{s}$ than at $10 \% / \mathrm{s}$ (Figures 3 and 4 ). These results were observed on the average of the five steady-state loading cycles, after five-preconditioning cycles for each deformation rate. However, similar results were also observed on the first loading cycle at each deformation rate, eliminating the possibility of this behavior being due to pre-conditioning. The experimental procedure was validated by repeating the same experiments on latex and nitrile samples. As expected, the effect of deformation rate was opposite in these rubbers to what was observed in the arterial samples. An experiment without any sample was performed to measure the combined effects of inertia, friction, and water drag force, which were found to be negligible, i.e. less than $10 \%$ of the effect of deformation rate.

Sample variability between circumferential and axial force vs. stretch ratio curves was found to be lower than the effect of deformation rate, supporting the use of an isotropic constitutive equation to predict the behavior of the arterial wall. Isotropic models have also been used to model the artery in other studies [43,47-50]. Forces instead of stresses were reported here due to the non-homogeneous stress and strain distributions found in speci- mens subjected to biaxial tests, where the highest and lowest stresses are found near the curved boundaries and near the center of the sample, respectively [51]. Moreover, researchers who are focused (like us) on experimental rather than theoretical work will appreciate to report the data as raw as possible.

The main constituents of arterial tissues are collagen and elastin. The elastic response of arteries is largely due to elastin because elastin is about 1000 times more extensible than collagen. The proportion of elastin to the other arterial constituents is the highest in the aorta. Elastin chains are crosslinked together to form rubberlike, elastic fibers [52]. Each elastin molecule uncoils into a more extended conformation when the fiber is stretched and recoils spontaneously as soon as the stretching force is relaxed. Its elasticity is based on changes in the entropy of the molecular chains, while the material is deformed. An imposed strain increases the order in the molecular network and thus decreases its entropy. According to the thermodynamic laws, the network would try to recover its former shape, increasing their entropy.

One possible explanation for the observed phenomenon is that when elastin is stretched at high rates it would attain a highly oriented conformation and as a result the cross-links would not be able to bear the load due to slippage. However, as the stretch occurs at lower rates, the elastin molecules would have more time ava- ilable to adjust in order to prevent slippage of the cross-links and as a result would be able to bear a higher load. This effect can be viewed as an energy dissipation effect where at high rates of stretching the energy is dissipated rather by the associative flow and the slippage between cross-links. At lower rates the energy dissipation is less. This effect is similar to the stretching behaviour of branched polymers when compared to that of their linear counterparts [53,54]. Here elastin at high extensional rates would behave more like a linear polymer where the linear polymers can slip one past the other to exhibit a reduced load mainly due to high oriented conformation imposed by the high stretching rate. On the other hand, elastin at low extensional rates would behave like a branched polymer where the presence of branches prevent cross-linking slippage and as a result bear higher loads.

Moreover, Trepat et al. [55] subjected human airway smooth muscle cells to a transient stretch-unstretch maneuver with zero residual macroscale strain, observing that the cell promptly fluidizes and then slowly resolidifies. Therefore, is it possible that changes in the alignment and configuration of adjacent fibers within the extracellular matrix occurs as soon as one fiber begins to shear over the other (i.e. fluid-like behavior), making softer the overall response in the tissue when stretching the arterial sample at the highest deformation rate (minimum relaxation in the tissue due to short testing time). At lower deformation rates, the fibers have more time to move back to their original configuration, thus restraining their ability to flow (stiffer response).

The constitutive equation selected here is capable of representing the nonlinear elastic behavior of the artery, including the effect of deformation rate, with only four parameters. It produces a unique curve fitting solution to experimental results for each deformation rate. More importantly, it was observed that Mooney Rivlin parameters $a_{10}$ and $a_{01}$ were not a function of the deformation rate. This could imply that they are related to the elastic behavior of the artery. A linear relationship was obtained between parameter $a_{30}$ and the deformation rate, where the partially elastic contribution is given by coefficient $A$ and the deformation rate response is given by coefficient $\hat{B}$.

As shown in Figure 9, the model better fits the biaxial data than the uniaxial data. Using higher weights for the uniaxial least square differences, it was possible to obtain a better fit for uniaxial data, at the expense of a deterioration of the fit for biaxial data. The use of material parameters $a_{11}$ and $a_{20}$ did not improve the fits significantly enough to justify increasing the complexity of 
the model with these two extra parameters. The use of anisotropic constitutive equations in future studies might reduce this discrepancy between predicted and experimental forces in uniaxial direction.

Clinical results have shown that slow balloon inflation might reduce restenosis. It was hypothesized that the slower deformation rate gives as a result lower intramural stresses and lower arterial injury. This hypothesis is contradictory to our results, which would indicate that a lower inflation rate would result in higher intramural stresses. Other mechanisms might play a role in leading to lower restenosis rates, such as endothelium denudation or artery injury being dependent on stretch ratio rather than on intramural stress.

\section{CONCLUSIONS}

In the present study, the effect of deformation rate on the mechanical behavior of arteries in vitro under uniaxial and biaxial extensions was investigated. It was found that the loading force at a stretch ratio of 1.5 is reduced by $20 \%$ when the deformation rate is increased from 10 to $200 \% / \mathrm{s}$, implying that the stiffness of arteries decreases with deformation rate. This behavior might be a consequence of the faster fluidization and small resolidification that occurs in the cell at higher deformation rates. This effect of deformation rate was observed to be higher than the effect of anisotropy. The development of an isotropic hyperelastic rate-dependent constitutive model, derived from the Mooney-Rivlin hyperelastic model, is capable of representing this behavior. In its proposed form, the model has only 4 parameters, only one of which varies with deformation rate. The small number of material parameters and simple formulation increase the applicability of this model to numerical simulations. The inverse relationship between stiffness and deformation rate raises doubts on the hypothesized relationship between intramural stress, arterial injury, and restenosis.

Future work might be helpful in order to account the entire loading history of the arterial wall by performing additional characterizations such as relaxation time experiments, and with the aim of a viscoelastic model. The ratio between maximum stretch with balloon and inflation time might be computed as well to observe if the same phenomenon appears.

\section{ACKNOWLEDGEMENTS}

This research was possible thanks to the $\mathrm{PhD}$ scholarship given by the Mexican Council of Science and Technology (Consejo Nacional de Ciencia y Tecnología), CONACYT. The authors would also like to thank Marc-Andre Rainville for his guidance and assistance in sample preparation and mechanical testing.

\section{REFERENCES}

[1] Thornton, G.M., Schwab, T.D. and Oxland, T.R. (2007a)
Fatigue is more damaging than creep in ligament revealed by modulus reduction and residual strength. Annals of Biomedical Engineering, 35, 1713-1721.

[2] Thornton, G.M., Schwab, T.D. and Oxland, T.R. (2007b) Cyclic loading causes master rupture and strain rate than static loading in medial collateral ligament at high stress. Clinical Biomechanics, 22, 932-940.

[3] Provenzano, P., Lakes, R., Keenan, T. and Vanderby Jr., R. (2001) Nonlinear ligament viscoelasticity. Annals of Biomedical Engineering, 29, 908-914.

[4] Pioletti, D. And Rakotomanana, L.R. (2000) Non-linear viscoelastic laws for soft biological tissues. Eur. J. Mech. A/Solids, 19, 749-759.

[5] Pioletti, D., Rakotomanana, L.R., Benvenuti, J.F. and Leyvraz, P.F. (1998) Viscoelastic constitutive law in large deformations: Application to human knee ligaments and tendons. Journal of Biomechanics, 31, 753-757.

[6] Kwan, M.K., Lin, T.H.C. and Woo, S.L.Y. (1993) On the viscoelastic properties of the anteromedial bundle of the anterior cruciate ligament. J. Biomechanics, 26, 447-452.

[7] Pioletti, D., Rakotomanana, L.R. and Leyvraz, P.F. (1999) Strain rate effect on the mechanical behavior of the anterior cruciate ligament-bone complex. Medical Engineering \& Physics, 21, 95-100.

[8] Haut, R.C. (1983) Age-dependent influence of strain rate on the tensile failure of rat-tail tandon. Journal of Biomechanical engineering, 105, 296-299.

[9] Haut, R.C. and Little, R.W. (1972) A constitutive equation for collagen fibers. Journal of Biomechanics, 5, 423430.

[10] Gay, R.E., Ilharreborde, B., Zhao, K., Boumediene, E. and An, K.N. (2008) The effect of loading rate and degeneration on neutral region motion in human cadaveric lumbar motion segments. Clinical Biomechanics, 23, 1-7.

[11] Wang, J.L., Parnianpour, M., Shirazi-Adl, A. and Engin, A.E. (1999) Rate effect on sharing of passive lumbar motion segment under load-controlled sagittal flexion: Viscoelastic finite element analysis. Theoretical and Applied Fracture Mechanics, 32, 119-128.

[12] Yingling, V.R., Callaghan, J.P. and McGill, S.M. (1997) Dynamic loading affects the mechanical properties and failure site of porcine spines. Clinical Biomechanics, 12, 301-305.

[13] Tran, N.T., Watson, N.A., Tencer, A.F., Ching, R.P. and Anderson, P.A. (1995) Mechanism of the burst fracture in the thoracolumbar spine: The effect of loading rate. Spine, 20, 1984-1988.

[14] De Smet, E., Jaecques, S.V.N., Jansen, J.J., Walboomers, F., Van Der Sloten, J. and Naert, I.E. (2007) Effect of constant strain rate, composed of varying amplitude and frequency, of early loading on peri-implant bone (re)modeling. Journal of Clinical Periodontology, 34, 618-624.

[15] Ebacher, V., Tang, C., McKay, H., Oxland, T.R., Guy, P. and Wang, R. (2007) Strain redistribution and cracking behavior of human bone during bending. Bone, 40, 12651275.

[16] Hsieh, Y.F., Wang, T. and Turner, C.H. (1999) Viscoelastic response of the rat loading model: Implications for studies of strain-adaptive bone formation. Bone, 25, 379382.

[17] Schaffler, M.B., Radin, E.L. and Burr, D.B. (1989) Me- 
chanical and morphological effects of strian rate on fatigue of compact bone. Bone, 10, 207-214.

[18] Hu, T. and Desai, J.P. (2004) Soft-tissue material properties under large deformation: Strain rate effect. Proceedings of the $26^{\text {th }}$ Annual International Conference of the IEEE EMBS, San Francisco, CA, USA (September 1-5, 2004), 2758-2761.

[19] Doehring, T.C., Carew, E.O. and Vesely, I. (2004) The effect of strain rate on the viscoelastic response of aortic valve tissue: A direct-fit approach. Annals of Biomedical Engineering, 32, 223-232.

[20] Wells, S. and Sacks, M.S. (2002) Effects of fixation pressure on the biaxial mechanical behavior of porcine bioprosthetic heart valves with long-term cyclic loading. Biomaterials, 23, 2389-2399.

[21] Demer, L.L. and Yin, F.C.P. (1983) Passive biaxial mechanical properties of isolated canine myocardium. Journal of Physiology, 339, 615-630.

[22] Giles, J.M., Black, A.E. and Bischoff, J.E. (2007) Anomalous rate dependence of the preconditioned response of soft tissue during load controlled deformation. Journal of Biomechanics, 40, 777-785.

[23] Nekouzadeh, A., Pryse, K.M., Elson, E.L. and Genin, G. M. (2007) A simplified approach to quasi-linear viscoelastic modeling. Journal of Biomechanics, 40, 3070-3078.

[24] Sarver, J.J., Robinson, P.S. and Elliott, D.M. (2003) Methods for quasi-linear viscoelastic modeling of soft tissue: Application to incremental stress-relaxation experiments. Journal of Biomechanical Engineering, 125, 754-785.

[25] Vena, P., Gastaldi, D. and Contro, R. (2006) A constituent-based model for the nonlinear viscoelastic behavior of ligaments. Journal of Biomechanical Engineering, 128, 449-457.

[26] Zhang, W., Chen, H.Y. and Kassab, G.S. (2007) A rateinsensitive linear viscoelastic model for soft tissues. Biomaterials, 28, 3579-3586.

[27] Schwartz, R.S., Holmes Jr., D.R. and Topol, E.J. (1992) The restenosis paradigm revisited: An alternative proposal for cellular mechanism. Journal of the American College of Cardiology, 20, 1284-1293.

[28] Tenaglia, A.N., Quigley, P.J., Kereiakes, D.J., Abbottsmith, C.W., Phillips, H.R., Tcheng, J.E., Rendall, D. and Ohman, E.M. (1992) Coronary angioplasty performed with gradual and prolonged inflation using a perfusion balloon catheter: Procedural success and restenosis rate. Am. Heart J., 124, 585-589.

[29] Miketic, S., Carlsson, J. and Tebbe, U. (1998) Influence of gradually increased slow balloon inflation on restenosis after coronary angioplasty. American Heart Journal, 135, 709-713.

[30] Timmis, S.B.H., Hermiller, J.B., Burns, W.H., Meyers, S. N. and Davidson, C.J. (1999) Comparison of immediate and in-hospital results of conventional balloon and perfusion balloon angioplasty using intracoronary ultrasound. American Journal of Cardiology, 83, 311-316.

[31] Eltchaninoff, H., Cribier, A., Koning, R., Chan, C., Jolly, N., Tan, A. and Letac, B. (1996) Effects of prolonged sequential balloon inflations on results of coronary angioplasty. Am. J. Cardiol, 77, 1062-1066.

[32] Ohman, E.M., Marquis, J.F., Ricci, D.R., Brown, R.I., Knudtson, M.L., Kereaikes, D.J., Samaha, J.K., Margolis, J.R., Niederman, A.L. and Dean, L.S. (1994) A random- ized comparison of the effects of gradual prolonged versus standard primary balloon inflation on early and late outcome: Results of a multicenter clinical trial. Perfusion balloon catheter study group, Circulation, 89, 1118-1125.

[33] Umeda, H., Iwase, M., Kanda, H., Izawa, H., Nagata, K., Ishiki, R., Sawada, K., Murohara, T. and Yokota, M. (2004) Promising efficacy of primary gradual and prolonged balloon angioplasty in small coronary arteries: A randomized comparison with cutting balloon angioplasty and conventional balloon angioplasty. American Heart Journal, 147, 1-8.

[34] Weiss, T., Leibovitz, D., Katz, I., Danenberg, C., Varshitsky, B. and Lotan, C. (2007) The value of computerized angioplasty in patients undergoing coronary stenting: A prospective, randomized trial. Am. J. Cardiol., 100, $118 \mathrm{~L}$.

[35] Thériault, P., Terriault, P., Brailovski, V. and Gallo, R. (2006) Finite element modeling of a progressively expanding shape memory stent. Journal of Biomechanics, 39, 2837-2844.

[36] Gasser, T.C. and Holzapfel, G.A. (2007) Modeling plaque fissuring and dissection during balloon angioplasty intervention. Annals of Biomedical Engineering, 35, 711723.

[37] Holzapfel, G.A., Stadler, M. and Schulze-Bauer, C.A (2002) A layer-specific three-dimensional model for the simulation of balloon angioplasty using magnetic resonance imaging and mechanical testing. Ann. Biomed. Eng, 30, 753-767.

[38] Lally, C., Dolan, F. and Prendergast, P.J. (2005) Cardiovascular stent design and vessel stresses: A finite element analysis. Journal of Biomechanics, 38, 1574-1581.

[39] Oh, S., Kleinberger, M. and McElhaney, J.H. (1994) Finite-element analysis of balloon angioplasty. Med. \& Biol. Eng. \& Comput., 32, S108-S114.

[40] Wu, W., Qi, M., Liu, X.P., Yang, D.Z. and Wang, W.Q. (2007) Delivery and release of nitinol stent in carotid artery and their interactions: A finite element analysis. Journal of Biomechanics, 40, 3034-3040.

[41] Lally, C., Reid, A.J. and Prendergast, P.J. (2004) Elastic behavior of porcine coronary artery tissue under uniaxial and equibiaxial tension. Ann. Biomed. Eng., 32, 13551364.

[42] Okamoto, R.J., Wagenseil, J.E., Delong, W.R., Peterson S.J., Kouchoukos, N.T. and Sundit III, T.M. (2002) Mechanical properties of dilated human ascending aorta. Ann. Biomed. Eng., 30, 624-635.

[43] Prendergast, P.J., Lally, C., Daly, S., Reid, A.J., Lee T. C., Quinn, D. and Dolan, F. (2003) Analysis of prolapse in cardiovascular stents: A constitutive equation for vascular tissue and finite-element modelling. Journal of Biomechanical Engineering, 125, 692-699.

[44] Waldman, S.D. and Lee, J.M. (2002) Boundary conditions during biaxial testing of planar connective tissues: Part 1: Dynamic behavior. Journal of Materials Science, Materials in Medicine, 13, 933-938.

[45] Fung, Y.C. (1993) Biomechanics: Mechanical properties of living tissues, $2^{\text {nd }}$ edition, Springer-Verlag, New York, 261-262.

[46] Mooney, M.A. (1940) Theory of large elastic deformation. J. Appl. Phys., 11, 582-592.

[47] Raghavan, M.L. and Vorp, D.A. (2000) Toward a bio- 
mechanical tool to evaluate rupture potential of abdominal aortic aneurysm: Identification of a finite strain constitutive model and evaluation of its applicability. Journal of Biomechanics, 33, 475-482.

[48] Scotti, C.M. and Finol, E.A. (2007) Compliant biomechanics of abdominal aortic aneurysms: A fluid-structure interaction study. Computers \& Structures, 85, 1097-1113.

[49] Tezduyar, T.E., Sathe, S., Cragin, T., Nanna, B., Conklin B.S., Pausewang, J. and Schwaab, M. (2007) Modelling of fluid-structure interactions with the space-time finite elements: Arterial fluid mechanics. Int. J. Num. Meth. Fluids, 54, 901-922.

[50] Wang, D.H.J., Makaroun, M., Webster, M.W. and Vorp, D.A. (2001) Mechanical properties and microstructure of intraluminal thrombus from abdominal aortic aneurysm. Journal of Biomechanical Engineering, 123, 536-539.

[51] Virues-Delgadillo, J.O., Delorme, S., Diraddo, R. and Hatzikiriakos, S.G. (2007) Effect of deformation rate on the mechanical properties of rectangular and cruciform arterial samples: Uniaxial and biaxial testing. Proceedings ASME 2007 Summer Bioengineering Conference Keystone, Colorado, USA.

[52] Shadwick, R.E. (1999) Mechanical design in arteries. $J$. Exp. Biol., 202, 3305-3313.

[53] McLeish, T.C.B. and Larson, R.G. (1998) Molecular constitutive equations for a class of branched polymers: The pom-pom model. J. Rheol, 42, 81-110.

[54] Sentmanat, M., Muliawan, E.B. and Hatzikiriakos, S.G. (2005) Fingerprinting the processing of polyethylenes from transient extensional flow and peel experiments in the melt state. Rheologica Acta, 44, 1-15.

[55] Trepat, X., Deng, L., An, S.S., Navajas, D., Tschumperlin, D.J., Gerthoffer, W.T., Butler, J.P. and Fredberg, J.J. (2007) Universal physical responses to stretch in the living cell. Nature, 447, 592-596. 